\title{
Influência da vitamina $D$ na atividade osteoclástica em um modelo de cultura de órgãos ósseos
}

\section{Influence of vitamin D on osteoclastic activity in a bone organ culture model}

Fernanda Ginani'; Carlos Augusto Galvão Barboza²

\begin{tabular}{l|l}
\multicolumn{1}{c|}{ unitermos } & res Um \\
\hline Osso & $\begin{array}{l}\text { Introdução: A remodelação óssea é regulada por várias citocinas e hormônios, como a vitamina D3. } \\
\text { Essa vitamina, em particular, regula positiva e negativamente a expressão do ligante do receptor } \\
\text { Vitamina D }\end{array}$ \\
Reabsorção óssea & $\begin{array}{l}\text { como um indutor da formação de osteoclastos in vitro. Objetivo: Estudar o efeito da vitamina D (VitD) } \\
\text { sobre a atividade osteoclástica em cultura de calvárias. Material e método: Fragmentos de calvária de } \\
\text { camundongos foram cultivados com meio básico (controle) ou com meio contendo VitD (10 nM: baixa } \\
\text { dose; } 100 \text { nM: alta dose). Após os intervalos de 24, } 48 \text { e } 72 \text { horas, o meio de cultura foi coletado para } \\
\text { dosagem de cálcio e os fragmentos foram fixados para análise em microscopia confocal. Resultados: } \\
\text { Observou-se que a adição de VitD nas duas dosagens promoveu aumento nos níveis de cálcio no } \\
\text { meio, porém só foram encontradas diferenças estatisticamente significativas entre alta e baixa dose no } \\
\text { intervalo de 24 horas. Na microscopia, foram observadas áreas de desmineralização mais amplas nos } \\
\text { fragmentos de calvária cultivados com altas doses de VitD. Conclusão: A VitD promove aumento da } \\
\text { atividade osteoclástica in vitro, de modo concentração-efeito. }\end{array}$
\end{tabular}

abstract

Introduction: Bone remodeling is controlled by various cytokines and hormones, such as vitamin D3, which regulates receptor activator of nuclear factor kappa-B ligand (RANKL) and osteoprotegerin (OPG) expression levels positively and negatively. It is also used as an inducer of osteoclast formation in vitro. Objective: To evaluate the effect of vitamin D (VitD) on osteoclastic activity in cultured calvariae. Material and method: Fragments of mice calvaria were cultured in basic medium (control) or VitD-containing medium (10 nM: low dose; 100 nM: high dose). After intervals of 24, 48 and 72 hours, the culture medium was collected for calcium measurement and the fragments were fixed for confocal microscopy. Results: It was observed that the addition of vitamin $D$ in both concentrations promoted an increase of calcium levels in the medium. Nonetheless, statistically significant differences between high and low doses were detected only in the 24-hour interval. In the microscopic analysis, areas of demineralization were more extensive among calvariae cultured with high doses of VitD. Conclusion: VitD increases osteoclastic activity in vitro in a dose-dependent effect.

\section{key words}

Bone

Vitamin D

Bone resorption

Calcium

1. Biomédica; mestranda do Programa de Pós-graduação em Odontologia da Universidade Federal do Rio Grande do Norte (UFRN).

2. Doutor em Patologia Bucal; professor adjunto do Departamento de Morfologia e do Programa de Pós-graduação em Odontologia da UFRN.

Suporte financeiro: Conselho Nacional de Desenvolvimento Científico e Tecnológico (CNPq). 


\section{Introdução}

O osso é um tecido mineralizado que confere múltiplas funções mecânicas e metabólicas ao esqueleto. $\mathrm{O}$ tecido ósseo sofre constante remodelação por meio da síntese de matriz pelos osteoblastos e da reabsorção pelos osteoclastos. A formação desse tecido envolve a proliferação e a diferenciação de células do estroma ao longo de uma via osteogênica de múltiplas etapas. Esse processo de diferenciação celular é controlado por uma cascata de eventos que abrange uma programação genética associada à regulação gênica por vários hormônios, citocinas e fatores de crescimento ${ }^{(24)}$. O osso é formado por dois métodos de diferenciação do mesênquima ${ }^{(12,21)}$ : ossificação intramembranosa ${ }^{(15,25)}$ e ossificação endocondra| ${ }^{(18,26)}$. Em ambos os tipos, a deposição de uma matriz extracelular característica pelos osteoblastos e sua mineralização por deposição de apatita são similares ${ }^{(21)}$.

A osteoclastogênese é regulada principalmente pelo fator estimulador de colônias de macrófagos (M-CSF), pelo ligante do receptor ativador do fator nuclear kappa-B (RANKL) e pela osteoprotegerina (OPG) . Na superfície dos monócitos, ocorre a expressão do RANK, que é o receptor para o ligante RANKL expresso na superfície dos osteoblastos. A ligação do RANK ao RANKL na presença do M-CSF induz a osteoclastogênese. A OPG é uma proteína expressa pelos osteoblastos, células estromais e outros tipos celulares, que inibe a formação e a atividade dos osteoclastos, ligando-se ao RANKL e impedindo sua ligação ao RANK(8).

Alguns hormônios, citocinas e fatores humorais podem influenciar a homeostase do cálcio e a densidade óssea por indução da expressão de RANKL no interior das células ósseas. Entre os fatores que ativam a remodelação óssea, a vitamina $D$ (VitD) é conhecida por induzir o aumento da reabsorção óssea e da hipercalcemia sérica ${ }^{(10)}$. Essa vitamina ocorre sob duas formas: o ergocalciferol ou vitamina $D_{2} e$ o colecalciferol ou vitamina $\mathrm{D}_{3}{ }^{(19)}$, sendo esta última sintetizada na pele pela influência da exposição à luz solar ou ultravioleta, hidroxilada no fígado em 25 -hidroxivitamina $\mathrm{D}_{3}$ (25D) e, posteriormente, no rim em 1,25-di-hidroxivitamina $D_{3}(1,25 D)$, que representa o metabólito ativo responsável pela estimulação da absorção de cálcio pelo intestino(13).

A administração de VitD em concentrações crescentes induz a diferenciação dos osteoclastos, que ocorre com a ligação do RANKL ao RANK, expresso na membrana das células hematopoéticas. Juntamente com essa ligação, o M-CSF induz a fusão dessas células, formando uma célula gigante multinucleada, o osteoclasto ${ }^{(1,23)}$. O osteoclasto formado atuará na remodelação óssea no período embrionário, além de agir na reabsorção e na liberação de cálcio para o organismo no osso já formado ${ }^{(19)}$.

Esses achados compreendem um avanço importante na busca pelo desenvolvimento de novas direções na terapia dos distúrbios ósseos humanos, como a osteoporose, e no tratamento de pacientes com metástase óssea. O objetivo deste trabalho foi avaliar a influência da dosagem de VitD na atividade de osteoclastos em um modelo de cultura de calvária de camundongos.

\section{Material e método}

\section{Procedimento de coleta das amostras}

Matrizes de camundongos albinos Swiss selvagens foram obtidas e acasaladas em condições adequadas, seguindo-se os princípios éticos na experimentação animal do Colégio Brasileiro de Experimentação Animal (COBEA). A presente pesquisa foi aprovada pelo Comitê de Ética no Uso de Animais da instituição.

Seis dias após o nascimento, os filhotes $(n=14)$ foram sacrificados para a obtenção das calvárias. Os fragmentos de calvária foram dissecados sob condições estéreis, englobando os ossos frontal e temporal e conservando-se o periósteo e o endósteo. Posteriormente, os fragmentos foram seccionados ao meio, totalizando 28 fragmentos.

\section{Cultivo dos órgãos ósseos}

Os espécimes de calvária foram divididos em grupo-controle (grupo I) e dois grupos experimentais (grupos II e III), cultivados em meio complementado com diferentes dosagens de VitD. Os órgãos ósseos foram ainda distribuídos em subgrupos, de acordo com o tempo de cultura: 24,48 e 72 horas.

No grupo I (controle), os fragmentos foram cultivados em meio essencial mínimo Eagle modificado alfa (alfa-MEM) sem nucleosídeos (Cultilab, Brasil), com $50 \mathrm{mg} / \mathrm{l}$ de sulfato de gentamicina e $2 \mathrm{mg} / \mathrm{l}$ de anfotericina B e complementado com $15 \%$ de soro equino (Sigma, EUA). Nos grupos II e III foram adicionados ao meio, respectivamente, $10 \mathrm{nM}$ (baixa dose) e $100 \mathrm{nM}$ (alta dose) de VitD (UofT, Canadá). Foram utilizados três fragmentos de calvária para cada intervalo de tempo em cada um dos grupos estudados.

Os órgãos foram cultivados individualmente em 300 microlitros de meio, em placas de cultura de 24 poços (TPP, Brasil), colocadas em uma estufa a $37^{\circ} \mathrm{C}$, com $5 \%$ de $\mathrm{CO}_{2}$ e $95 \%$ de umidade. 
Decorridos os tempos experimentais, os fragmentos foram fixados em solução de paraformaldeído a $4 \%$ e corados por Alizarin Red para avaliação microscópica das áreas mineralizadas por meio de microscopia confocal. A cada intervalo de tempo, o meio foi coletado e o nível de cálcio foi dosado por espectrofotometria.

\section{Análise dos resultados}

Os níveis de cálcio dos diferentes grupos e intervalos de tempo foram submetidos ao teste estatístico de análise de variância (ANOVA) , com nível de significância de $5 \%$. As imagens obtidas na microscopia confocal foram analisadas com auxílio do software de histomorfometria Image ProPlus 7 (Media Cybernetics, EUA).

\section{Resultados}

A adição de VitD nas duas dosagens promoveu aumento expressivo nos níveis de cálcio no meio, ao longo das 72 horas do experimento, conforme mostra a Figura 1. Após aplicação do teste de ANOVA, foi encontrada diferença estatisticamente significativa $(p<0,05)$ entre alta e baixa dose no intervalo de 24 horas (Figura 1). Já a análise dos dados nos intervalos de 48 e 72 horas não revelou diferenças estatisticamente significativas entre os grupos com diferentes dosagens de VitD.

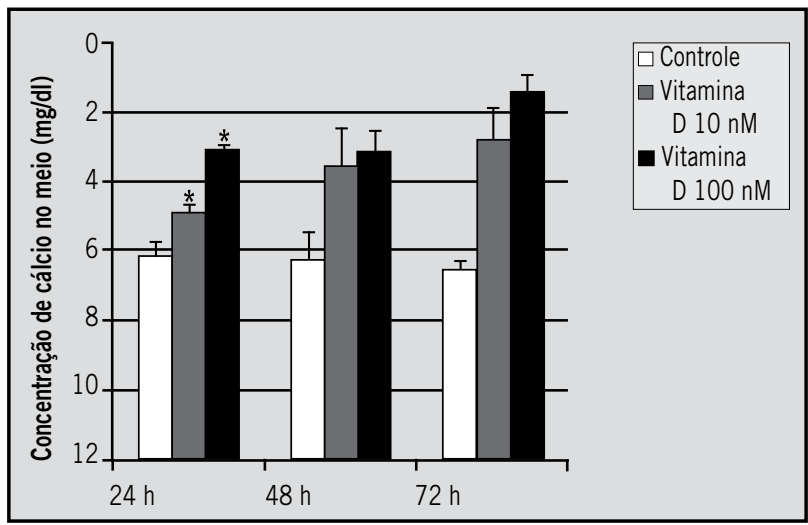

Figura 1 - Concentração de cálcio no meio de cultura nos diferentes grupos e nos intervalos de 24, 48 e 72 horas

${ }^{*} p=0,0010$.

Na microscopia confocal, observou-se a presença de áreas focais de desmineralização mais amplas nos fragmentos de calvária cultivados com altas doses de VitD, quando em comparação com os fragmentos de calvária cultivados com baixas doses (Figura 2).

As médias das áreas de desmineralização encontradas na histomorfometria são apresentadas na Tabela a seguir.

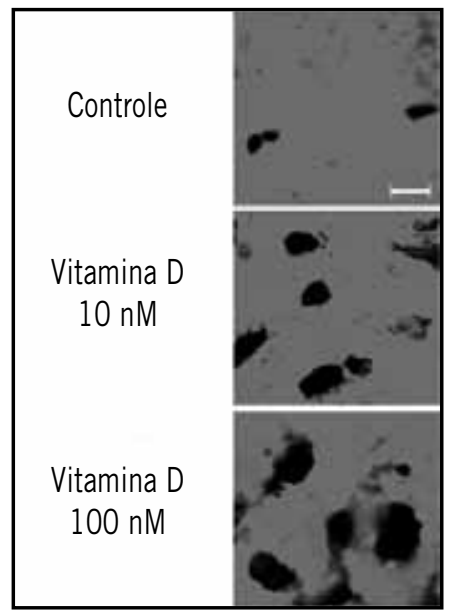

Figura 2 - Coloração de Alizarin Red em calvárias cultivadas na ausência de vitamina $D$ (controle) e com diferentes dosagens de vitamina $D$ por 72 horas

As áreas escuras representam as lacunas de reabsorção óssea (microscopia confocal; barra $=50 \mu \mathrm{m})$.

Áreas de desmineralização nos grupos Tabela no intervalo de 72 horas

\begin{tabular}{c|c}
\hline Grupos & Áreas de desmineralização $\left(\mu \mathrm{m}^{2}\right)$ \\
\hline Controle & 4.168 \\
Baixa dose & 25.112 \\
Alta dose & 47.560 \\
\hline
\end{tabular}

\section{Discussão}

O tecido ósseo funciona como depósito de cálcio e outros íons, armazenando-os ou liberando-os de maneira controlada para manter constante sua concentração sérica. A VitD representa um fator importante para o desenvolvimento e crescimento ósseos, além de manter a homeostase de cálcio e fosfato, tendo em vista que uma de suas principais funções é facilitar os processos para manter um esqueleto saudável ${ }^{(17)}$. Essa vitamina atua no DNA das células de revestimento do intestino delgado, induzindo a síntese do RNA mensageiro, responsável pela codificação da proteína transportadora de cálcio através da membrana celular. Isso possibilita o intercâmbio constante de cálcio dos ossos com o dos líquidos extracelulares, já que este é responsável por realizar funções básicas, como a contração muscular e a condução de impulsos nervosos ${ }^{(11)}$.

$\mathrm{O}$ primeiro estudo com VitD em um modelo animal demonstrou que ela poderia prevenir o raquitismo experimental em ratos ${ }^{(20)}$. Posteriormente, novos trabalhos foram realizados, demonstrando unanimidade no que diz respeito ao aumento da absorção de cálcio no epitélio gastrointestinal decorrente da ação dessa vitamina ${ }^{(19)}$. 
Com o avanço nas pesquisas, foi comprovado que a VitD in vivo atua nos osteoblastos, promovendo a síntese de RANKL, que é expresso em sua superfície. As células hematopoéticas da linhagem monócito/macrófago expressam em suas superfícies o receptor (RANK) para o RANKL. A ligação na superfície óssea entre RANK e RANKL, na presença do fator estimulador de colônias de macrófagos (M-CSF), induz a osteoclastogênese ${ }^{(1,23)}$. A resposta dos osteoblastos à VitD pode variar, dependendo do estágio de diferenciação dessas células: células imaturas respondem a partir de uma ação osteoclástica evidenciada pela expressão de RANKL; nas células maduras, a resposta é osteogênica ${ }^{(6)}$. Já existem elementos suficientes que demonstram que tanto as respostas osteogênicas quanto as osteoclastogênicas por osteoblastos podem ser reguladas por níveis de VitD circulantes in vivo(5).

Neste trabalho, avaliamos o efeito da VitD em diferentes dosagens na atividade osteoclástica em um modelo de cultura in vitro. Nossos resultados confirmaram os achados de Notoya et al. ${ }^{(23)}$ e Altundag et al.(1), mostrando que a adição de doses crescentes de VitD promove aumento expressivo nos níveis de cálcio no meio, quando em comparação com o grupo-controle. Esses achados demonstram que a administração, in vitro, de VitD promove a diferenciação dos osteoclastos a partir de células precursoras e, em altas doses, eleva a reabsorção óssea mediada por osteoclastos. Este último efeito é dependente do aumento da produção de RANKL pelos osteoblastos, fator-chave necessário para a diferenciação e a ativação dos osteoclastos ${ }^{(4)}$.

Além disso, foi demonstrado também que a elevação da atividade osteoclástica in vitro é dose-dependente, ou seja, quanto maior a dose de VitD, maior será o nível de cálcio no meio, e as lacunas de reabsorção serão mais amplas. Portanto, a VitD funciona como um agente de ativação dos osteoclastos, que secretam ácidos e enzimas que atacam a matriz e, consequentemente, liberam cálcio para o meio, além de participarem da eliminação dos restos de tecido ósseo que se formam durante a reabsorção do osso ${ }^{(9)}$.

O mecanismo de ação da VitD sobre a osteogênese tem sido elucidado nos últimos anos. Sabe-se que as células da linhagem osteoblástica controlam a diferenciação osteoclástica por meio do eixo RANKL/OPG e a 1,25D (forma ativa da vitamina) estimula, preferencialmente, a expressão de RANKL em osteoblastos imaturos, como demonstrado no estudo de Kogawa et al. ${ }^{(16)}$. Esse mesmo estudo forneceu evidências de que o metabolismo da VitD em osteoclastos, de forma autócrina, e os níveis circulantes de 25D parecem ser determinantes na diferenciação do osteoclasto e sua função.

Em modelo de animal de depleção de VitD, a correlação entre níveis circulantes de $25 \mathrm{D}$ e volume mineral ósseo está intimamente associada a um declínio na atividade osteoclástica. Apenas nos animais com níveis superiores a $80 \mathrm{nmol} / \mathrm{l}(32 \mathrm{ng} / \mathrm{mol})$ de $25 \mathrm{D}$ não houve queda na atividade osteoclástica e no volume ósseo ${ }^{(3)}$. A partir dessa observação, demonstra-se que o nível sérico de 25D é um dos principais determinantes do volume ósseo ${ }^{(2)}$ e também regula os níveis de RANKL e a reabsorção óssea ${ }^{(3)}$.

Para a remodelação óssea, que ocorre de forma contínua durante toda a vida, e para o aumento das concentrações séricas de cálcio, é necessário que ocorra o mecanismo de reabsorção óssea ${ }^{(19)}$ e a VitD apresenta um papel importante nesses processos. Fu et al. demonstraram, mediante estudos em ratas ovariectomizadas, que o calo ósseo formado em fraturas induzidas apresenta maior resistência biomecânica no grupo em que houve administração de VitD via oral. Isso se deve ao acúmulo de VitD no local do calo ósseo, fazendo com que haja aumento da concentração de cálcio no local da lesão. Além disso, foi demonstrado no mesmo estudo que a VitD atua limitando o crescimento microestrutural do calo, o que comprova sua ação na remodelação óssea ${ }^{(14)}$.

Need et al. relatam que a queda dos níveis circulantes de 25D promove a elevação da concentração sérica de paratormônio (PTH) e 1,25D como resposta inicial. A combinação de 1,25D e PTH é conhecida como um potente estimulador da formação de osteoclastos e da reabsorção óssea. Assim, a diminuição dos níveis de 25D in vivo pode promover a perda óssea por mecanismos endócrinos. Em virtude disso, as alterações nos níveis de 25D têm importantes efeitos sobre o esqueleto, resultando na interação entre osteoblastos e osteoclastos, impulsionado pelo metabolismo da VitD no microambiente ósseo. $\mathrm{O}$ equilíbrio na quantidade dessa vitamina presente no corpo é importante, já que sua produção excessiva ou insuficiente provoca significativos distúrbios ${ }^{(22)}$. A literatura mostra que uma intoxicação por VitD (hipervitaminose D) pode acarretar maior desmineralização óssea com consequente fragilidade dessas estruturas mineralizadas. Já quando ocorre baixa ingestão de VitD (hipovitaminose D), há anormalidades na mineralização, devido à baixa disponibilidade de cálcio e fosfato, além da redução da função dos osteoblastos, o que resulta em raquitismo ou osteomalacia $^{(7)}$. 
Como demonstrado, níveis adequados de VitD e seu metabolismo são importantes em vários aspectos para a saúde óssea do esqueleto, tendo em vista que já foi comprovado que a 25D otimiza tanto a diferenciação osteoblástica quanto a mineralização óssea ${ }^{(5)}$. Assim, estudos experimentais in vivo com diferentes níveis de VitD mostram-se promissores na terapia das patologias do tecido ósseo e de suas implicações clínicas.

\section{Conclusão}

A adição de VitD ao meio de cultura promove aumento da atividade osteoclástica in vitro no modelo experimental estudado, de modo concentração-efeito: quanto mais alta a dose, maior o nível de cálcio liberado e mais amplas são as lacunas de reabsorção observadas no tecido ósseo.

\section{Referências}

1. ALTUNDAG, O. etal. Calcium and vitamin D supplementation during bisphosphonate administration may increase osteoclastic activity in patients with bone metastasis. Med Hypotheses, v. 63, n. 6, p. 1010-3, 2004.

2. ANDERSON, P. H. et al. 25-hydroxyvitamin D requirement for maintaining skeletal health utilising a SpragueDawley rat model. J Steroid Biochem Mol Biol, v. 103, n. 3-5, p. 592-5, 2007

3. ANDERSON, P. H. et al. Vitamin D depletion induces RANKL-mediated osteoclastogenesis and bone loss in a rodent model. J Bone Miner Res, v. 23, n. 11, p. 1789-97, 2008.

4. ANDRESEN, C. et al. Action of calciotropic hormones on bone metabolism: role of vitamin D3 in bone remodeling events. Am J Immunol, v. 2, n. 2, p. 40-51, 2006.

5. ATKINS, G. J. et al. Metabolism of vitamin D3 in human osteoblasts: evidence for autocrine and paracrine activities of 1 alpha,25-dihydroxyvitamin D3. Bone, v. 40, n. 6, p. 1517-28, 2007.

6. ATKINS, G. J. et al. RANKL expression is related to the differentiation state of human osteoblasts. J Bone Miner Res, v. 18, n. 6, p. 1088-98, 2003.

7. BARRAL, D.; BARROS, A. C.; ARAUJO, R. P. C. Vitamina D: uma abordagem molecular. Pesq Bras Odontoped Clin Integr, v. 7, n. 3, p. 309-15, 2007.

8. BLAIR, H. C.; ATHANASOU, N. A. Recent advances in osteoclast biology and pathological bone resorption. Histol Histopathol, v. 19, n. 1, p. 189-99, 2004.

9. BLAIR, H. C.; ZAIDI, M. Osteoclastic differentiation and function regulated by old and new pathways. Rev Endocr Metab Disord, v. 7, n. 1-2, p. 23-32, 2006.

10. BOYLE, W. J.; SIMONET, W. S.; LACEY, D. L. Osteoclast differentiation and activation. Nature, v. 423, n. 6937 , p. 337-42, 2003.

11. BRONNER, F. Extracellular and intracellular regulation of calcium homeostasis. Scientific World Journal, v. 1 , p. 919-25, 2001.

12. DUCY, P.; SCHINKE, T.; KARSENTY, G. The osteoblast: a sophisticated fibroblast under central surveillance. Science, v. 289, n. 5484, p. 1501-4, 2000.

13. FELDMAN, D.; PIKE, J. W.; GLORIEUX, F. H. Vitamin D. San Diego, CA: Elsevier Academic Press, 2005.

14. FU, L. et al. Effect of 1,25-dihydroxy vitamin D on fracture healing and bone remodeling in ovariectomized rat femora. Bone, v. 44, n. 5, p. 893-8, 2009.
15. KATCHBURIAN, E.; ARANA, V. Histologia e embriologia oral: texto, atlas, correlações clínicas. São Paulo: Guanabara Koogan, 2004.

16. KOGAWA, M. et al. Osteoclastic metabolism of $25(\mathrm{OH})$ vitamin $D_{3}$ : a potential mechanism for optimization of bone resorption. Endocrinology, v. 151, n. 10, p. 4613-25, 2010.

17. KOGAWA, M. et al. The metabolism of $25-(\mathrm{OH})$ vitamin D3 by osteoclasts and their precursors regulates the differentiation of osteoclasts. J Steroid Biochem Mol Biol, n. 121, v. 1-2, p. 277-8, 2010.

18. KRONENBERG, H. M. Developmental regulation of the growth plate. Nature, v. 423, n. 6937, p. 332-6, 2003.

19. LIPS, P. Vitamin D physiology. Prog Biophys Mol Biol, v. 92, n. 1, p. 4-8, 2006.

20. MCCOLLUM, E. V. The paths to the discovery of vitamins A and D. J Nutr, v. 91, n. 2, p. 11-6, 1967.

21. NAKASHIMA, K.; DE CROMBRUGGHE, B. Transcriptional mechanisms in osteoblast differentiation and bone formation. Trends Genet, v. 19, n. 8, p. 458-66, 2003.

22. NEED, A. G. et al. The effects of age and other variables on serum parathyroid hormone in postmenopausal women attending an osteoporosis center. J Clin Endocrinol Metab, v. 89, n. 4, p. 1646-9, 2004.

23. NOTOYA, M. et al. Runx-2 is not essential for the vitamin D-regulated expression of RANKL and osteoprotegerin in osteoblastic cells. Biochem Biophys Res Commun, v. 324, n. 2, p. 655-60, 2004.

24. SODEK, J.; MCKEE, M. D. Molecular and cellular biology of alveolar bone. Periodontol 2000, v. 24, p. 99-126, 2000.

25. SPERBER, G. H. Craniofacial development. Hamilton: BC Decker Inc., 2001

26. YANG, X.; KARSENTY, G. Transcription factors in bone: developmental and pathological aspects. Trends $\mathrm{Mol}$ Med, v. 8, n. 7, p. 340-5, 2003 